Dr. Moravesik explains very clearly the vital importance of establishing fundamental scientific research in these countries on any adequate scale and the practical difficulties of doing so in the face of competing interests, limited resources and the shortage of trained scientists. Without this the effort in applied science is unlikely to be either adequate or sustained. All this, he insists, must be firmly based in the developing countries themselves and, following very closely the line of Dr. Dedijer's argument, he insists that the need can only be met with an adequato and carefully planned programme of the technical assist. ance covering buildings, equipment and man-power. His article makes a most timely and pertinent comment on the recommendations of the Bawden Committee and the Minister's statement thereon, and it is to be hoped that it will bo most carefully considored by Mr. Carr and his advisers. Even 200 scientists, as Dr. Moravesik points out in his final sentence, distributed over 50 underdeveloped countrios ready to benefit from such a programme as he outlines - assentially that contemplated in the Whito Papers-would make a tremendous impact on fundamental research all over the world and in the long run pay a very large return in the form of the scientific results obtained from the institutions and the countries to which they go. Is Britain really so blind and improvident as to let the Ovorseas Research Council go ?

\section{STUDENT OF THE STARS}

William Herschel and the Construction of the Heavens By Dr. Michael A. Hoskin. With Astrophysical Notes by Dr. D. W. Dewhirst. (Oldbourne History of Science Library.) Pp. 199+8 plates. (London: Oldbourne Book Co., 1963.) 35s.

$\mathbf{T}$ is not often that a scientist who regards himself as 1 almost entirely a collector of facts can transform the structural framework of his science; yet it does happen now and again, and William Herschel (1738-1822) is a notable example. Herschel, the self-taught telescope maker and observational astronomer, spent nearly forty years in making sweeps of selected areas of the sky, counting, cataloguing and classifying the objects he observed, and thereby revolutionized the subject-matter of astronomy. Before Herschel's work, all astronomy not devoted to an examination of the solar system was concerned with 'mapping' the constellations, that is to say, with identifying, describing and locating the maximum number of objects against which cometary and planetary motion was observed and judged. Except for Halley's detection of the proper motion of three stars in 1718 - and he was not certain that there had truly been motion in this case-sidereal astronomy remained virtually untouched. Herschel achieved contemporary fame and a modest affluence as the discoverer of a new planet in 1781although, as is well known, he did not at first recognize its nature and was not allowed in the subsequent history of astronomy to call it after his royal patron-but it is as the student of the stars in the decades that followed that he has achieved posthumous fame. For he was thus led to notice, to investigate and to try to understand individual stars, pairs of stars, star systems and anomolous stars and to try to speculate on their place and role in the universe.

Nothing better illustrates the extraordinarily perceptive quality of Herschel's approach to astronomy than his transformation of the content of Messier's catalogue. Where Messier saw in these objects merely a trap for comet. collectors, Herschel saw in them a legitimate sphere for telescopic investigation. He could not at first know (and was always reluctant to admit) that these 'nebulæ' were of various varieties, but sheer persistence in the patient telescopic examination in which he excelled ultimately led him to have a pretty good idea of the difference between ring nebulæ, nebulosities, star clusters, globular clusters and galaxies. It is no exaggeration to insist that he was "the onlie begetter" of modern extra. galactic astronomy, especially when one considers his attempts to classify his nebulæ on an evolutionary scale and to try to use their distribution in defining the outline of our Galaxy (his 'heavens').

Taking his title from Herschel's paper of 1784 , in which Herschel described how a new and powerful tolescope had enabled him, by examining the clustering of stars and (apparently) resolving all nebulæ, to pave the way for a theory of the shape of the Milky Way, Dr. Hoskin has compiled an account of Herschel's many and varied attempts to understand "The Construction of the Heavens" based in large part on Herschel's own writings.

The important papers of $1784,1785,1789,1811$ and 1815 , all originally published in the Philosophical Trans. actions, are given substantially in full at the end of the appropriate chapters (though in regrettably fine print). There are liberal quotations from these and other papers in the main body of the text, which is virtually a summary of Herschel's astronomical achievement. Herschel nevor wrote a book, or a synthesis of his major work, or indeed any paper which summed up his many and varied views on the composition of the sidereal universe, but Dr. Hoskin may be said to have done it for him. Dr. David Dewhirst has supplied helpful identifications of Herschel's nebulæ; indeed these are so precise and illuminating that one regrets the lack of a pietorial comparison between Herschel's sketches (many reproduced here) and modern photographs where his sketches are identifiable. This would have aided the modern reader in comprehending even more sympathetically than the text permits the difficulties Herschel had to overcome in order to discover the variety which existed in the superficially similar objects which he investigated.

Astronomers will find this a most fascinating brief presentation of the theoretical intuitions of one of the greatest observational astronomers. No scientist can fail to bo absorbed in the attempt by an empiricist to solve theoretical problems of pioneering cosmological significance, an attempt which altered the nature of the examination of the stars. MARIE BOAS HALI

\section{ABATEMENT OF AIR POLLUTION}

\section{Control of Air Pollution}

By Alan Gilpin. Pp. xiii + 514. (London: Butterworth and Co. (Publishers), Ltd., 1963.) $120 s$.

$T$

HIS book is essentially a practical one dealing with present practice in the major industrial processes which produce air pollution in England. It covers aspects of this subject that are of importance to the public health inspector and his trainee and which are not adequately dealt with elsewhere. As such it will find a place as a reference book in most local authority offices and many industrial organizations that have an interest in clean air. The author, A. Gilpin, is well qualified to write this book, as he was formerly a chief public health inspector and is now with the Central Electricity Generating Board, where he will be able to assess the impact on air pollution of the largest single consumer of fuel in Britain.

The book is divided into four main sections. The first of these defines the major pollutants, mentions briefly their effects and deseribes the various methods by which they are measured. The second part is headed "Furnaees, Fuels and Firing Methods" and covers somo 200 pages. Although this section is doubtless necessary to make the book complete for its purpose, most of the information it contains has already been well covered in other publications. 